\title{
The new era of biotech insulin analogues
}

\section{J. B range}

Novo Nordisk A/S, Bagsvaerd, Denmark

Summary Many of the structural properties of insulin have evolved in response to the requirements of biosynthesis, processing, transport and storage in the pancreatic beta cells, properties that are not necessary for the biological action of the hormone. It is therefore not surprising that wild-type insulin has far from optimal characteristics for replacement therapy. For example, native human insulin self-associates to hexameric units, which limits the possibilities for the absorption of the molecule by various routes. During the last decade new techniques of molecular design have emerged and recombinant DNA technology offers new and exciting opportunities for rational pro- tein drug design. This review describes examples of recent advances in insulin engineering aimed at optimizing the hormone for therapy. Such approaches focus on improvements in the pharmacokinetic properties, storage stability, and feasibility for less intrusive routes of administration [Diabetologia (1997) 40: S 48-S53].

Keywords Insulin therapy, insulin analogues, monomeric insulin, protein engineering, chemical stability, iontophoresis, transdermal delivery, non-invasive administration.
The introduction of insulin in the 1920 s revolutionized the treatment of diabetes mellitus. However, pancreatic insulin did not evolve for exogenous administration, and subcutaneous injection therapy has not succeeded in normalizing glycaemic control despite the great efforts devoted to improvements in insulin preparations and injection regimens. The increasing awareness and acceptance of the relationship between metabolic control and the occurrence of devastating microvascular complications have stimulated considerable research into new methods of improving insulin therapy.

In the field of pharmaceutical formulation important improvements have emerged. However, the pharmacokinetics following subcutaneous injection of the currently available rapid-, intermediate- and long-acting insulin preparations make it virtually impossible to achieve normoglycaemia. The absorption

Corresponding author: Dr. J. Brange, Novo Nordisk A/S, Building 6A, Novo Alle, DK-2880 Bagsvaerd, Denmark of insulin from the injection site is a complex process affected by many factors, such as location of the site, physical state of the patient and the nature of the insulin preparation. After subcutaneous injection of regular insulin into the femoral region it takes $2-4 \mathrm{~h}$ for the insulin to be absorbed at maximum rate. This slow rise to peak insulin concentration is likely to account for much of the observed postprandial hyperglycaemia seen in diabetic subjects. As the insulin concentration falls slowly after the peak, the extended period of elevated insulin concentration results in a tendency towards late hypoglycaemia. Such plasma insulin patterns bear no resemblance to those in normal subjects in response to a meal. After subcutaneous injection of soluble insulin an initial phase (lag phase) with low but increasing relative rate of absorption has been observed in most clinical studies. This initial delay in absorption is shortened or even disappears when reducing the concentration of insulin or decreasing the volume injected [1].

Until recently advances in insulin formulation were limited to improvements in insulin purity, insulin 
species, and adjustment of the composition of the preparation with respect to retarding agent and other excipients. Advances in genetics and molecular biology have now provided convenient methods for introducing changes into a native protein. Thus, recombinant DNA technology has made it possible to 'engineer' modifications into the amino acid sequence of insulin enabling production of insulin analogues with the intention to investigate the role of the individual amino acid in the molecular assembly, biological activity and therapeutic properties. Three examples of potential advances achievable by insulin engineering', relating to improved pharmacokinetics, storage stability and efficacy for non-invasive administration, are reviewed here.

\section{Fast-acting, monomeric insulins}

Native human insulin associates above physiologic concentrations into dimers and hexamers, an inherent property which limits the possibilities for the absorption of the molecule by various routes [2]. Hexamerization of the insulin molecule facilitates biosynthesis and pancreatic intracellular storage of insulin, but is unnecessary for interaction of insulin as a monomer with its receptor. Therefore, experiments to create insulins with reduced self-association were undertaken $[3,4]$. A rational approach to insulin engineering requires detailed knowledge about the conformation of the molecule and its modes of interaction at the atomic level within and between subunits. Using computer-aided molecular modelling and recombinant DNA technology a series of human insulin analogues with reduced tendency to self-association has been developed. The original principles for the selective replacement of amino acid residues have been to influence charge effects and hydrophobic interactions, or to introduce steric hindrance at the interfaces between associating subunits in the insulin hexamer [4].

The main strategy followed was to introduce charge repulsion into the interfaces, and negative charges (amino acids with carboxylic acids in the side chain) have been used in most cases. Side chain carboxyl groups (Asp or Glu residues) in some cases already exist adjacent to the interface and have been chosen as opponents to an inserted negative charge in the opposite unit. One example is the $\mathrm{Asp}^{\mathrm{B} 28}$ analogue in which substitution of Pro with the charged aspartic acid creates repulsion from the glutamic acid in position B28 in the adjacent monomer in the dimer. More recently, manipulation of the structure of the B-chain, aiming at decreasing its potential for $\beta$-sheet interactions of the peptide backbone between insulin monomers, has resulted in insulins with decreased tendency to self-association. Examples of such analogues are the LysPro insulin [5] in which the sequence of the $\mathrm{B} 28$ and $\mathrm{B} 29$ residues are

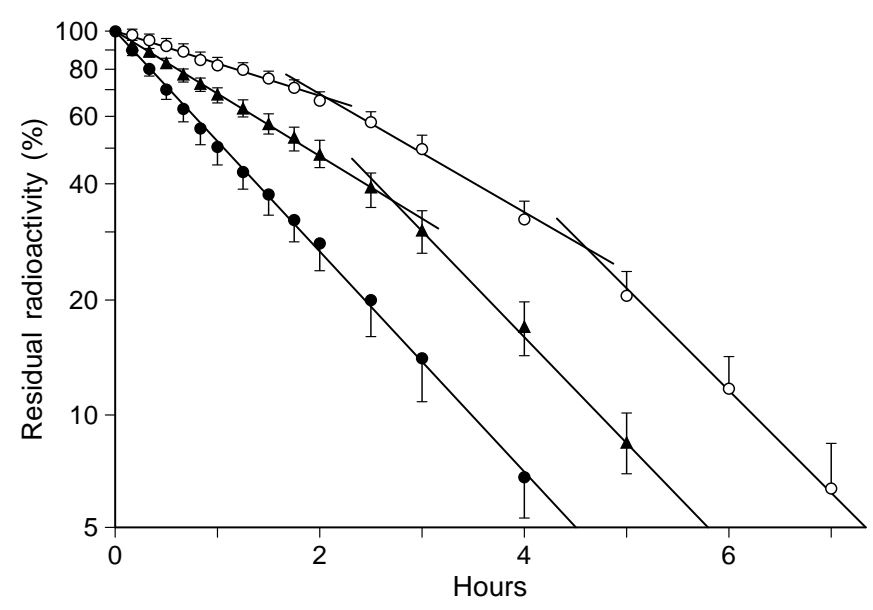

Fig. 1. Semilogarithmic plot of disapperance curves (means \pm SEM) of hexameric human insulin $(\bigcirc)$, dimeric insulin analogue $\operatorname{Asp}^{\mathrm{B} 10}(\boldsymbol{\Delta})$, and monomeric insulin analogue $\mathrm{Asp}^{\mathrm{B} 9}$, $\mathrm{Glu}^{\mathrm{B} 27}(\mathrm{O})$ in normal subjects $(\mathrm{n}=7)$. Residual radioactivity at the injection site was measured by external counting after s.c. administration of ${ }^{125}$ I-labelled insulins at doses of $0.1 \mathrm{IU} /$ $\mathrm{kg}$. Straight line segments were calculated by linear regression analysis. Reproduced with permission from [7]

reversed, and analogues characterized by deletion of one of the amino acid residues in the B25 to B28 sequence [6].

The Asp ${ }^{\mathrm{B} 28}$ insulin analogue, now selected for major clinical trials, is able to crystallize as a hexamer in the presence of zinc and calcium ions that together cancel the repulsive effect of the Asp mutation. Analyses by X-ray crystallography have revealed that the structure of the analogue is essentially identical to that of the native human insulin (G. Dodson, personal communication).

Following the demonstration in pigs [7], that the rate of subcutaneous absorption is inversely correlated to the degree of insulin self-association, a number of clinical studies of insulin analogues intended for meal-related therapy were performed in normal subjects. Subcutaneous administration of less associated insulins leads to more rapid rises in plasma insulin concentrations and resulting hypoglycaemic responses when compared with human insulin in the same formulation [8-13]. Thus, monomeric insulins were absorbed three times faster than human insulin, had no lag phase and followed a monoexponential course throughout the absorption process. In contrast, three phases in rate of absorption were identified for the normal hexameric human insulin $[7,10]$ (Fig. 1).

These studies confirmed a major influence of the insulin association state on the rate of absorption of subcutaneously injected soluble insulin. This factor seems to be the main determinant of the influence of insulin species and concentration, injected volume and, at least partly, the effects of increased temperature (more dissociated insulin) and of massage (faster 


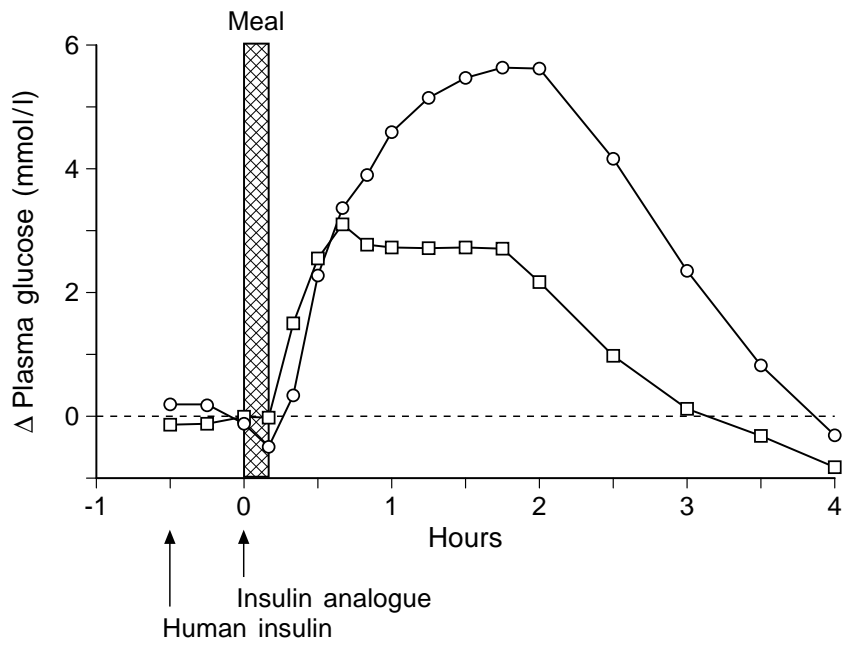

i.v. infusion

Fig. 2. Mean incremental plasma glucose concentrations following a test meal $(500 \mathrm{kcal})$ in insulin-dependent diabetic subjects $(n=6)$ after injection of $72 \mathrm{nmol}$ s. c. regular human insulin $(\bigcirc)$ at time -30 min and $72 \mathrm{nmol}$ of insulin analogue $\mathrm{Asp}^{\mathrm{B} 28}$ $(\square)$ at time $0 \mathrm{~h}$ while receiving constant insulin infusion of $0.12 \mathrm{mIU} \cdot \mathrm{min}^{-1} \cdot \mathrm{kg}^{-1}$ human regular insulin. Data from [17]

Fig. 3. Schematic overview of the chemical transformations affecting insulin during storage (adapted from [27]) dispersion and dilution of the insulin depot). The initial delay in reaching maximal absorption rate (lag phase), i. e. the time until the absorption follows first order kinetics, can now also be fully or mainly explained by the time necessary for sufficient dilution and subsequent dissociation of hexameric insulin into smaller units. Because of the very low concentration required for further dissociation into monomers the fraction of soluble native insulin absorbed in monomeric form is small. In contrast, the monomeric insulin analogues follow a monoexponential disappearance course right from the time of injection and the slope of the disappearance curve, i.e. rate of disappearance, is much steeper than that of the initial part of the disappearance curve for human insulin. Thus, the availability of the monomeric insulins has contributed significantly to our understanding of the processes involved in subcutaneous insulin absorption [7, $10]$.

Using a mathematical model [2] adapted to monomeric insulin it has been shown that the absorption rate of monomeric insulin, in contrast to that of human insulin, is not expected to be dependent on insulin concentration, injected volume or depth of injection [14]. In accordance with this model, clinical data [8] show an unchanged absorption profile of monomeric insulin with a doubling of dose (volume). Also, the accelerating effect of massage, exercise and temperature on the rate of absorption of regular insulin is presumably reduced with monomeric insulins as compared to human insulin, suggesting that

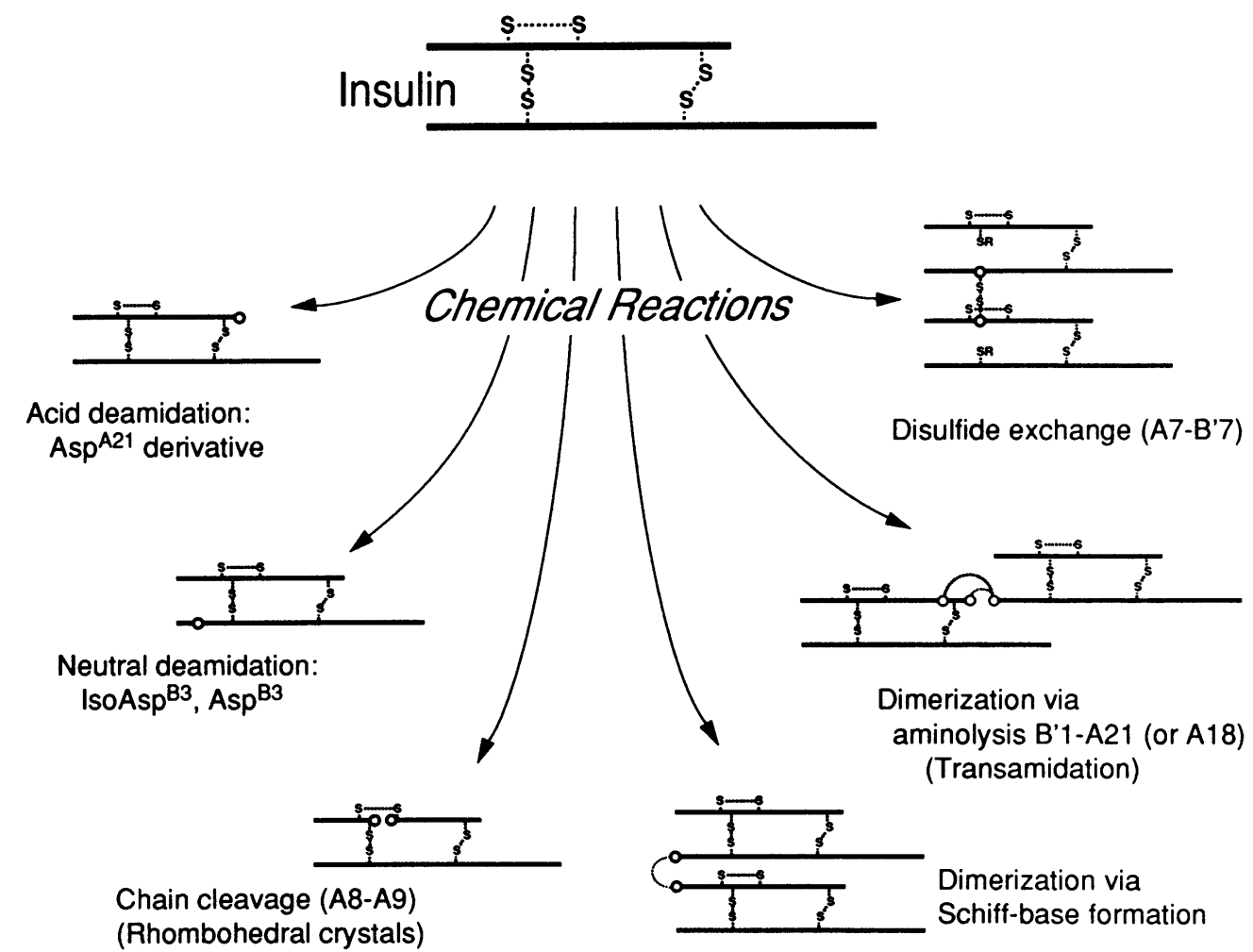




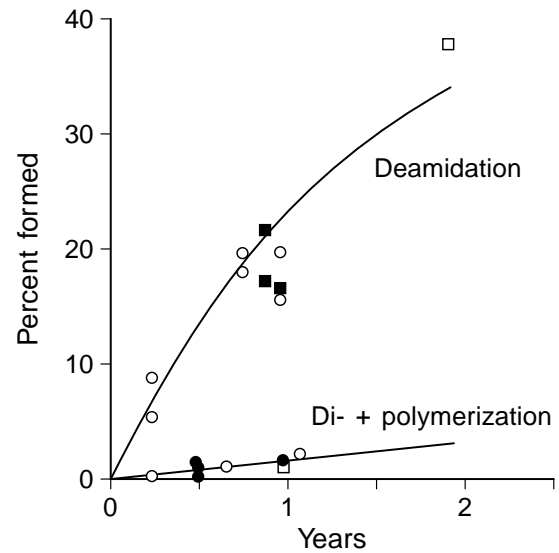

Fig. 4. Chemical transformation of insulin during storage of regular insulin at $25^{\circ} \mathrm{C}$. The curves represent mean formation of degradation products in preparations of porcine insulin at $40 \mathrm{IU} / \mathrm{ml}$. Points represent preparations in IU 80 ( $)$ and IU 500 strength $(\bigcirc)$ formulated with human $(\bigcirc)$ and bovine $(\square)$ insulin (data from [27])

the use of monomeric insulin may contribute to less day-to-day variation in absorption. With respect to the influence of temperature these expectations have been confirmed in sauna studies [15].

Studies in insulin-dependent diabetic patients have demonstrated the beneficial pharmacokinetics and significant therapeutic value of monomeric insulin analogues [7, 16-19]. They yield a degree of glycaemic control, when injected just before a meal, at least comparable to that of human insulin administered 30 min before the meal [7, 17]. Administration of insulin analogue $\mathrm{Asp}^{\mathrm{B} 28}$ resulted in a substantial reduction in the postprandial glucose excursion compared with that of human insulin injected $30 \mathrm{~min}$ earlier (Fig.2). Relative to regular human insulin $(100 \pm 17 \%)$ the plasma glucose area under the curve for the analogue was $51 \pm 16 \%(p<0.02)$ [17]. Because of the more rapid decline in serum hormone concentrations one might also expect the risk of late hypoglycaemia to be reduced with the monomeric analogues.

\section{Insulins with improved chemical stability}

Insulin is not a stable chemical entity and a variety of chemical changes of the primary structure (yielding insulin derivatives) affect insulin and insulin preparations during handling, storage and use (Fig. 3). Insulin decomposition is mainly due to two categories of chemical reactions: hydrolysis and intermolecular transformation leading to covalent insulin dimers. The predominant hydrolysis reaction in neutral preparations is deamidation of the $\mathrm{Asn}^{\mathrm{B} 3}$ residue [21], and the covalent dimers are mainly formed via intermolecular aminolysis between an N-terminal amine in insulin and an amide side chain in the insulin A-chain
Table 1. Design of chemically stable insulins

\begin{tabular}{lll}
\hline Insulin & \multicolumn{2}{l}{$\begin{array}{l}\text { Formation of degradation products } \\
\left(\% \text { after } 1 \text { month at } 37^{\circ} \mathrm{C}\right)\end{array}$} \\
\cline { 2 - 3 } & Covalent dimer & Desamido insulin \\
\hline Human & 1.1 & 3.1 \\
A21Gly, B3Asp & 0.9 & 1.3 \\
A15Glu, A18Asp, B3Asp & 0.4 & 0.1 \\
A21Gly, B3Gln & 0.1 & \\
\hline
\end{tabular}

Data obtained from [28]

of another molecule [22]. The transformations occur independent of species of insulin, and of strength of the preparation (Fig. 3).

Deamidation causes transformation of larger amounts of insulin than the dimerization reactions (Fig. 4). On the other hand, the molecular changes induced by deamidation are relatively small and the deamidation products have essentially the same in vivo biological potency and immunological properties as the intact molecule [23]. In contrast, the dimerization products have reduced biological potency, and some of the immunological side effects associated with insulin therapy have been asserted to be due to the presence of such covalent aggregates of insulin in the therapeutic preparations [24-26].

Knowledge of the potential residues undergoing chemical changes during storage [27] has allowed the design of insulin analogues with improved properties with respect to chemical stability. Thus, by substituting $\mathrm{Asn}^{\mathrm{B} 3}$ by Gln, and $\mathrm{Asn}^{\mathrm{A} 21}$ by Ala or Gly, the resulting insulin analogue showed 30 times less deamidation and 10 times reduced formation of covalent insulin dimers [28] (Table 1). The advantages of such preparations are improved shelf-life and more convenient storage temperatures. Whether reduced covalent dimerization leads to less immunological side effects remains to be seen.

\section{Insulins for transdermal delivery by iontophoresis}

The potential of using the skin as a drug delivery route has been recognized for several decades, but the skin is an efficient barrier to the penetration of ionic and hydrophilic substances and large molecules. However, if an appropriate electrical potential is applied across the skin, the electric current can carry ionized drug molecules across the barrier, probably through discrete pores like the sweat glands and hair-follicles [29]. This technique, iontophoresis, which has been known for about a century, is presently receiving considerable attention from both academia and industry because of the wish for a non-invasive and non-parenteral administration form for new peptide drugs. The delivery rate is dependent on current density, electrode area and drug concentration and can be controlled by adjusting the current [30]. 


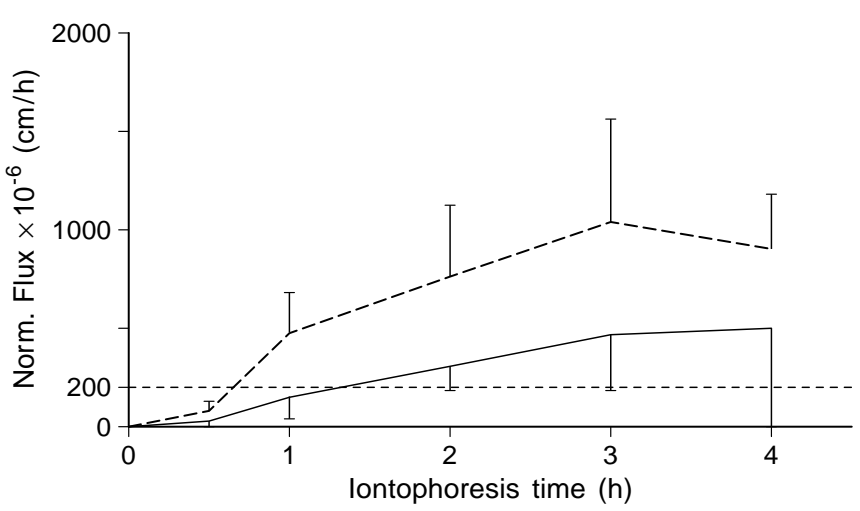

Fig. 5. Transdermal, iontophoretic transport of insulin analogues $\mathrm{Asp}^{\mathrm{B} 9}, \mathrm{Glu}^{\mathrm{B} 27}(-)$ and $\mathrm{Glu}^{\mathrm{B} 16}, \mathrm{Glu}^{\mathrm{B} 27}(--)$ through freshly excised mouse skin in vitro. The skin was wiped gently with ethanol prior to iontophoresis which was performed with constant direct current $\left(0.5 \mathrm{~mA} / \mathrm{cm}^{2}\right)$. The broken straight line represents delivery of $1 \mathrm{IU} / \mathrm{h}$, sufficient to cover an average diabetic patient's need for basal insulin supply, based on the assumption of a $10-\mathrm{cm}^{2}$ patch. (Langkjær et al., unpublished data)

Transdermal iontophoretic transport of normal, hexameric insulin through rodent skin in vitro has been reported to be very low [31] and far from clinically relevant. Several in vivo experiments with transdermal, iontophoretic delivery into diabetic pigs, rabbits and hairless rats have been reported [32-38] using variable current densities, formulation and polarity. Stephen et al. [32] could not detect any effect after cathodal iontophoresis of porcine (hexameric) insulin, whereas with a monomeric, highly ionized sulphated insulin therapeutic plasma hormone levels were obtained in a single diabetic pig. Systemic insulin delivery to rats has been studied by Chien and coworkers [34-36]. Based on the reduction in blood glucose, enhanced iontophoretic transport was reported of positively charged, and less aggregated insulin at $\mathrm{pH} 3.6$ as compared to negatively charged, hexameric insulin at neutral $\mathrm{pH}$. Therapeutic serum insulin levels were observed in studies of iontophoretic delivery to diabetic rabbits [37]. However, the rate of systemic delivery of the hexameric insulin was approximately 10 times less than that required for basal rate delivery to an average weight human.

In contrast, recent preliminary in vitro investigations using hairless mouse skin have indicated that specific monomeric insulin analogues may be transdermally transported by iontophoresis with rates sufficient to cover the basal need for a typical diabetic patient (Fig.5). It was also observed that an increase in net charge (substitution with aspartate or glutamate residues) resulted in enhanced insulin delivery. To obtain clinically relevant doses it was necessary to wipe the skin gently with absolute ethanol prior to iontophoresis, a procedure expected to solubilize and remove some of the lipids (sebum) blocking the hair-follicles. In these experiments it was found that monomeric insulins with at least two additional negative charges (substitution of at least two amino acid residues by Glu or Asp) were delivered more than 100 times more efficiently across hairless mouse skin than hexameric, human insulin [38]. Thus, the novel insulins with reduced tendency to association have the added potential of improving also the absorption by alternative routes of administration.

\section{Conclusions}

Recent advances in redesigning of the insulin molecule have opened up new possibilities for better replacement therapy. The therapeutic need to improve the hormone's pharmacokinetic properties, storage stability and suitability for less intrusive routes of administration is increasingly being addressed through the development of insulin analogues by protein engineering.

\section{References}

1. Binder C (1969) Absorption of injected insulin. Acta Pharmacol Toxicol [Suppl 2]:1-87

2. Mosekilde E, Jensen KS, Binder C, Pramming S, Thorsteinsson B (1989) Modeling absorption kinetics of subcutaneous injected soluble insulin. J Pharmacokinet Biopharm 17: 67-87

3. Brange J, Diers I, Hansen J, et al. (1987) Monomeric insulins by protein engineering. Protein Engn 1: 250 (Abstract)

4. Brange J, Ribel U, Hansen JF, et al. (1988) Monomeric insulins obtained by protein engineering and their medical implications. Nature 333: 679-682

5. Brems DN, Alter LA, Beckage MJ, et al. (1992) Altering the association properties of insulin by amino acid replacement. Protein Eng 5: 527-533

6. Balschmidt P, Brange J (1992) Fast acting human insulin analogues with a single amino acid deletion in the B-chain. Diabetologia 35 [Suppl 1]:A4 (Abstract)

7. Brange J, Owens DR, Kang S, Vølund A (1990) Monomeric insulins, and their experimental and clinical implications. Diabetes Care 13: 923-954

8. Vora JP, Owens DR, Dolben J, et al. (1988) Recombinant DNA derived monomeric insulin analogue: comparison with soluble human insulin in normal subjects. BMJ 297: 1236-1239

9. Heinemann L, Starke AAR, Heding L, Jensen I, Berger M (1990) Action profile of fast onset insulin analogues. Diabetologia 33: 384-386

10. Kang S, Brange J, Burch A, Vølund A, Owens DR (1991) Subcutaneous insulin absorption explained by insulin's physicochemical properties. Evidence from absorption studies of soluble human insulin and insulin analogues in humans. Diabetes Care 14: 942-948

11. Kang S, Brange J, Burch A, Vølund A, Owens DR (1991) Absorption kinetics and action profiles of subcutaneously administered insulin analogues (AspB9GluB27, AspB10, AspB28) in healthy subjects. Diabetes Care 14: 10571065

12. Heinemann L, Heise T, Jorgensen LN, Starke AAR (1993) Action profile of the rapid acting insulin analogue: human insulin B28Asp. Diabet Med 10: 535-539 
13. Howey DC, Bowsher RR, Brunelle RL, Woodworth JR (1994) [Lys(B28), Pro(B29)]-human insulin. A rapidly absorbed analogue of human insulin. Diabetes 43: 396-402

14. Trajanoski Z, Watch P, Kotanko P, Ott A, Skraba F (1993) Pharmacokinetic model for the absorption of subcutaneously injected soluble insulin and monomer insulin analogues. Biomed Tech 38: 224-231

15. Pöyry K, Kostamo E, Karonen S (1995) The effect of Finnish sauna on the absorption of short-acting insulin analogue. Diabetes 44[Suppl 1]:106A (Abstract)

16. Kang S, Owens DR, Vora JP, Brange J (1990) Recombinant DNA derived insulin analogue B9AspB27Glu: comparison with soluble human insulin in insulin treated diabetics. Lancet 335: 303-306

17. Kang S, Creag FM, Peters JR, Brange J, Vølund A, Owens DR (1991) Comparison of subcutaneous soluble human insulin and insulin analogues (AspB9, GluB27; AspB10; AspB28) on meal-related plasma glucose excursions in type I diabetic subjects. Diabetes Care 14: 571-577

18. Wiefels K, Kuglin B, Hübinger A, Jorgensen LN, Gries FA (1993) Insulin kinetics and dynamics in insulin-dependent diabetic patients after injections of human insulin or the insulin analogues X14 and X14 + Zn. In: Berger M, Gries FA (eds) Frontiers in insulin pharmacology. Thieme, Stuttgart New York, pp 97-101

19. Luttermann JA, Pijpers E, Netten PM, Jørgensen LN (1993) Glycaemic control in IDDM patients during one day with injection of human insulin or the insulin analogues insulin X14 and insulin X14 ( + Zn). In: Berger M, Gries FA (eds) Frontiers in insulin pharmacology. Thieme, Stuttgart New York, pp. 102-109

20. Brange J, Langkjær L (1993) Insulin structure and stability. In: Wang YJ, Pearlman R (eds) Stability and characterization of protein and peptide drugs: case histories. Plenum Press, New York, pp. 315-350

21. Brange J, Langkjær L, Havelund S, Vølund A (1992) Chemical stability of insulin: 1. Hydrolytic degradation during storage of pharmaceutical preparations. Pharm Res 9: 715-726

22. Brange J, Havelund S, Hougaard P (1992) Chemical stability of insulin: 2. Formation of higher molecular weight transformation products during storage of pharmaceutical insulin preparations. Pharm Res 9: 727-734

23. Brange J, Hallund O, Sørensen E (1992) Chemical stability of insulin: 5. Isolation, characterization and identification of insulin transformation products. Acta Pharm Nord 4: 223-232

24. Ratner RE, Phillips TM, Steiner M (1990) Persistent cutaneous insulin allergy resulting from high-molecular-weight insulin aggregates. Diabetes 39: 728-733
25. Robbins DC, Cooper SM, Fineberg SE, Mead PM (1987) Antibodies to covalent aggregates of insulin in blood of insulin-using diabetic patients. Diabetes 36: 838-841

26. Robbins DC, Mead PM (1987) Free covalent aggregates of therapeutic insulin in the blood of insulin-dependent diabetics. Diabetes 36: 147-151

27. Brange J (1994) Stability of insulin. Studies on the physical and chemical stability of insulin in pharmaceutical formulation. Thesis, Royal Danish School of Pharmacy, MTP Press, Lancaster

28. Brange J, Havelund S (1991) Novel insulin analogues stabilized against chemical modifications. European Patent No. 0419504

29. Cullander C (1992) What are the pathways of iontophoretic current flow through mammalian skin? Adv Drug Del Rev 9: $119-135$

30. Sage BH Jr, Riviere JE (1992) Model systems in iontophoresis - transport efficacy. Adv Drug Delivery Rev 9: 265-287

31. Banga AK, Chien YW (1993) Characterisation of in vitro transdermal iontophoretic delivery of insulin. Drug Dev Ind Pharm 19: 2069-2087

32. Stephen RL, Petelenz TJ, Jacobsen SC (1984) Potential novel methods for insulin administration: I. Iontophoresis. Biomed Biochim Acta 43: 553-558

33. Kari B (1986) Control of blood glucose levels in alloxan diabetic rabbits by iontophoresis of insulin. Diabetes 35: 217 221

34. Siddiqui O, Sun Y, Liu J-C, Chien YW (1987) Facilitated transdermal transport of insulin. J Pharm Sci 76: 341-345

35. Chien YW, Siddiqui O, Sun Y, Shi WM, Liu JC (1987) Transdermal iontophoretic delivery of therapeutic peptides/proteins. I: Insulin. Ann NY Acad Sci 507: 32-50

36. Liu J-C, Sun Y, Siddiqui O, Chien YW, Shi WM, Li J (1988) Blood glucose control in diabetic rats by transdermal iontophoretic delivery of insulin. Int J Pharmaceutics 44: 197204

37. Meyer BR, Katzeff HL, Eschbach JC et al. (1989) Transdermal delivery of human insulin to albino rabbits using electrical current. Am J Med Sci 297: 321-325

38. Chien YW (1991) Transdermal route of peptide and protein drug delivery. In: Lee VHL (ed) Peptide and protein drug delivery. Dekker, New York Basel Hong Kong pp 667-689

39. Langkjær L, Brange J, Grodsky GM, Guy RH (1994) Transdermal delivery of monomeric insulin analogues by iontophoresis. Proceed Intern Symp Control Rel Bioact Mater 21: $172-173$ 